\title{
Reflections on the Sendai Framework for Disaster Risk Reduction: Five Years Since Its Adoption
}

\author{
Mami Mizutori ${ }^{1}$
}

Published online: 23 March 2020

(C) The Author(s) 2020

Five years ago, on 18 March 2015, member states of the United Nations (UN) adopted the Sendai Framework for Disaster Risk Reduction 2015-2030 (United Nations Office for Disaster Risk Reduction 2015) in Sendai, Japan, a city still recovering from the Great East Japan Earthquake and Tsunami. Launched in the same year as the Agenda 2030, and the first of the landmark series of global agreements that were adopted during that year, the Sendai Framework marked a clear shift from managing the impact of disasters to managing and reducing risks that lead to disasters. In other words, a shift from reaction to prevention. This makes the Sendai Framework much more ambitious to implement and monitor than its predecessor, the Hyogo Framework for Action 2005-2015 (United Nations Office for Disaster Risk Reduction 2005). The Sendai Framework clearly states that in order to reduce the frequency and impact of disasters, what is required is to better understand disaster risk and to improve risk governance so that existing risks are reduced, and the creation of new risks is minimized. This is no easy feat to accomplish. It requires establishing consistent access to and collection of disaggregated data and strengthening capacity for contextually analyzing risk assessment and forecasting data. Most importantly, it requires building political will and action to ensure that all development programming and future investments are risk-informed.

Five years on, the purpose of this article is to take stock of where we are in meeting the initial procedural and data requirements for the Sendai Framework, and to reflect on

Mami Mizutori

http://www.undrr.org

1 Special Representative of the United Nations SecretaryGeneral for Disaster Risk Reduction, Geneva, Switzerland the lessons learned in the process. In what follows, I detail how the process demanded from the member states has operated, what support the United Nations Office for Disaster Risk Reduction (UNDRR) has been providing, where we stand today, and the challenges we face.

Since outlier events, like a high-impact disaster could result in massive losses and damage despite the best prevention efforts, it is important to track losses over a sufficient time period to gauge if disaster risk reduction interventions have paid off. The Sendai Framework recommends comparing disaster losses sustained between 2005 and 2015 with 2015 and 2030. Given this time frame, and the fact that it includes the end point of the Sendai Framework-2030_ongoing monitoring is essential. Without the availability of and access to historic disaster loss data together with future projections, it will not be possible to reach definitive conclusions about whether implementing disaster risk reduction interventions has resulted in a reduction in disaster-related loss and damage relative to the absence of these efforts.

The Sendai Framework identifies four priorities for action, and its focus on prevention is concretized in seven targets for member states to achieve. Four of the seven targets $(\mathrm{a}-\mathrm{d})$ are outcome-focused-seeking reduction in human and material losses from disasters. ${ }^{1}$ The remaining three targets $(\mathrm{e}-\mathrm{g})$ are input-focused-pursuing nationallyled and owned mechanisms to reduce disaster risk. ${ }^{2}$ The priorities for action include understanding risk in all its

\footnotetext{
${ }^{1}$ Human and material losses in the first four targets of the Sendai Framework include the number of persons dead and missing, the number of persons affected, economic losses, damage and destruction of infrastructure, and disruption of basic services.

2 The mechanisms for reducing disaster risk include national and local disaster risk reduction strategies in line with the Sendai Framework, international cooperation, and multi-hazard early warning systems.
} 
dimensions, guiding and incentivizing both public and private sectors to address disaster risk through strengthened risk governance, putting in place multi-hazard early warning systems, protecting productive assets, improving the safety and functionality of critical infrastructure, and strengthening disaster preparedness.

Following the adoption of this ambitious agenda, in June 2015, the United Nations General Assembly set up an Open-ended Intergovernmental Expert Working Group (OIEWG) to agree on indicators and terminology relating to disaster risk reduction. At the end of an intense consultation process, OIEWG identified 38 indicators to monitor progress in achieving the Sendai Framework's seven targets (United Nations General Assembly 2016).

To enable and guide global reporting on the seven targets against the 38 indicators, on 1 March 2018, UNDRR launched the online Sendai Framework Monitor (SFM) system in all six United Nations official languages along with a set of technical guidance notes for member states. To ensure that national reporting on Targets (a)-(d) is based on reliable, event-based data on disaster losses, UNDRR also retrofitted the existing DesInventar ${ }^{3}$ database for disaster loss to align its input interface with the data requirements for these targets.

To support member states' government officials to begin to use the SFM system and the new DesInventar database, UNDRR resourced its five regional offices with staff and budget to offer trainings, guidance, and customized support in recording and reporting relevant data. Between July 2018 and July 2019, UNDRR trained designated national Sendai Framework focal points, national statistics offices, government personnel, and civil society representatives from more than 100 countries on the use of the SFM and the collection and interpretation of disaster loss data. Furthermore, 1480 national and local government officials and other stakeholders from 107 countries were trained in person or online through UNDRR's Global Education and Training Institute (GETI) (United Nations General Assembly 2019). These efforts were complemented by key partner UN agencies and institutions of UNDRR including the United Nations Development Programme (UNDP), the Asian Disaster Preparedness Centre, the CIMA Foundation, ${ }^{4}$ and OSSO Cooperation. ${ }^{5}$

Understanding disaster risk - the first of the Sendai Framework's four priorities-has been particularly challenging. Several regional bodies have stepped up to assist

\footnotetext{
${ }^{3}$ DesInventar is a database and tool for recording disaster loss and damage data by event and locality. It is free and based on open source software. The original DesInventar datasets are available at https:// desinventar.org. The Sendai-aligned version of DesInventar can be accessed at https://desinventar.net.

${ }^{4}$ https://www.cimafoundation.org/.

5 https://www.osso.org.co/.
}

countries in improving their disaster risk understanding. The European Commission compiles a regional risk overview based on national risk assessments of 34 countries. The African Union is initiating an African science and technology disaster risk reduction advisory group, and as a result 25 countries of sub-Saharan Africa now have online disaster loss databases and 16 have developed their risk profiles. As for the second priority on strengthening disaster risk governance some countries have started putting in place legal frameworks covering disaster risk reduction and response that is crucially important. And while the importance of investing in disaster risk reduction (DRR) for resilience-the third priority for action in the Sendai Framework-is universally acknowledged, financing such investments has so far proved to be difficult.

Significant progress has been made in the Sendai Framework implementation monitoring. By end-September 2019,113 countries were already reporting at least partially for 2017, and 104 countries had started reporting for 2018. Of these 104 countries, 47 were least developed countries (LDCs), 21 were land-locked developing countries (LLDCs), and five were small island developing states (SIDS). Thus $51 \%$ of all LDCs, $66 \%$ of all LLDCs, and $21 \%$ of all SIDS had started reporting the latest data within 18 months of the process having commenced. Given the lack of human and financial resources and capacity in many of these countries, these numbers are quite impressive.

Prioritizing the accounting of human losses, most countries have started reporting on Target (a) - the number of persons dead and missing attributed to disasters. The 82 countries that reported on this target in 2018 had a combined population of 4.0 billion people-over half the global population. Moreover, 72 countries reported on Target (b) - the number of people affected by disasters. However, fewer countries have reported on disaster-related economic and infrastructure losses, reflecting the difficulty to gather data around these targets.

Foundational to reducing human and material losses from disasters is Sendai Framework Target (e)—to substantially increase the number of countries with national and local DRR strategies by 2020. Using the SFM system, member states are required to assess the alignment of their national DRR strategies against 10 parameters to arrive at an aggregated score on a scale of zero to one. By endSeptember 2019, 101 countries had undertaken this exercise and have reported that a national strategy is in place. Among them 81 countries reported some degree of alignment of their respective national DRR strategies with the Sendai Framework. Six countries assessed their national DRR strategies at full compliance with the Sendai Framework principles and 29 countries assessed their strategies as having a high degree of alignment. 
While these initial achievements are noteworthy, it is far from satisfactory. The 2020 deadline for the achievement of Target (e) is looming. Many countries are yet to start reporting on any target, and the majority of reporting countries are far from completing their coverage of all 38 indicators.

Through enhanced support to member states, UNDRR has set an ambitious target to assist 150 countries in developing their national DRR strategies, and to raise the average alignment score of all reporting countries to 0.75 by 2021 . Both the number of member states with national DRR strategies and their quality need to be improved.

Several lessons have emerged in the process of learningby-doing in these past 24 months since the SFM system started to operate. They range from the nature of risk, including climate risk, to the state of disaster-related statistics.

First, as the Sendai Framework states, the era of hazardby-hazard risk reduction is over. To address the reality we live in characterized by the systemic nature of risk, it is imperative to move away from working on distinct areas of risk, for example, spatial, geographic, temporal, disciplinary, when designing and implementing interventions, and instead adopt a coherent, coordinated approach across sectors. Recognizing that risk reduction cannot occur without climate action has become more than clear; disaster risk reduction will not be successful without coherence with climate change adaptation. Indeed, coordinated implementation of development objectives has the potential to deliver resilience to a wider range of threats and risks. Further benefits of coherent approaches include transaction cost reduction due to overlapping activities and duplicated data collection and reporting. The parallel development of the global agendas, the Sendai Framework, the Paris Agreement under the United Nations Framework Convention on Climate Change (Paris Agreement), and the Sustainable Development Goals (SDGs), resulted in limited alignment across the agreements with different actions and commitments across levels. Since the implementation of these agendas began, it has become evident that institutionalization of coherent approaches has to replace the business-as-usual/silo approaches in order to build synergies and mutually beneficial opportunities across policies and practices.

The UNDRR, together with other UN system agencies, is therefore making a global push to ensure that new and existing national DRR strategies are coherent with climate change policies globally, regionally, and, importantly, at the country level.

More specifically, UNDRR, together with the United Nations Framework Convention on Climate Change (UNFCCC) and other relevant partners, is working to promote policy coherence and integrated national plans to accelerate action towards the implementation of both the Sendai Framework and the Paris Agreement within the framework and towards the achievement of the SDGs. This effort focuses on building national capacities to create development and implementation synergies of national and local DRR strategies and the National Adaptation Plans (NAPs) associated with the Paris Agreement. Aligned planning can ensure that disaster risk reduction, climate action, and sustainable development policies lead to "leaving no one behind". This focus on coherence is a vital step in ensuring an integrated approach to implementing and monitoring risk-informed and climate-sensitive development plans.

Compounding this need for a coherent approach is the fact that the present world faces a plurality of risks. Emergent risks are multidimensional, and in a globalized world, harder to contain within national borders. Effective risk reduction will need both systems thinking, and localized vulnerability analysis and mitigation. Fostering systems thinking and pre-emptive risk analysis will require both a change in mindsets, and capacity at the national level to use available data for forward-looking risk assessments and decision making. To foster systems thinking and empower decision makers with appropriate tools for risk assessment and mitigation, UNDRR has initiated the development of a global risk assessment framework (GRAF) informed by national experiences, and expertise of practitioners, policymakers, and academics. The GRAF is envisaged to provide decision makers with actionable insights and access to products, tools, demonstrations, and scenarios at different spatial and temporal scales to better understand, reduce, and mitigate risk in the world of cascading and systemic risk.

In this evolving risk scenario, data are foundational to understanding risk and tracking risk reduction progress. Competent, capacitated institutions and rigorous mechanisms for data collection and for converting these into statistics are critical. As too is ensuring that decision makers have the necessary data available to them when it matters. In many countries, disaster loss data are collected by different ministries and institutions, while the mandate for disaster response and management lies with a separate entity-often located in the Ministry of Civil Protection or the Prime Minister's office. A contributor to the SFM system may not always be aware of what data are available and where to find them even in his or her own country. Absence of such information and formal channels of communication between the reporting entity, the Sendai focal point, and national and local data custodians hinders timely and accurate Sendai Framework reporting. To tackle this challenge, UNDRR has conducted training and peer exchange workshops generating opportunities for sharing 
experiences and enabling improved inter-ministerial coordination for DRR.

With the field of disaster-related statistics still in its infancy, the challenge of data quality affects most data sources. Most disaster-related databases combine data generated from a wide variety of sources and methods that are not necessarily comparable. Consequently, estimates of losses from different sources can diverge widely.

On the flipside, efforts to rigorously define and articulate the method for a variable can bring high returns on investment in terms of volume of reporting and data quality. For instance, an important component of direct economic losses [Target (c)] is agricultural sector losses. The method for estimating direct losses in the agricultural sector attributed to disasters has been rigorously defined by the United Nations Food and Agricultural Organization (FAO). Furthermore, both FAO and UNDRR have offered training to national SFM focal points on the method. As a result, both quality and coverage of data on agricultural losses are significantly higher than economic losses in any other sector, including the infrastructure sector. Direct agricultural losses reported on the SFM account for over $70 \%$ of total losses. Greater engagement of national statistical offices in collection and processing of these disaster-related data, enabled through this process, is an encouraging development.

Political will to overcome intra-governmental silos has emerged as a key driver of success not just in reporting data, but also in implementing risk-informed DRR plans. Such political will manifests in some cases in the creation of legal mandates to support DRR, and in other cases in establishing strong formal institutional arrangements. Many successful national initiatives integrate disaster data collection, reporting, and analysis with DRR interventions.

For instance, Qatar has sought to foster inter-ministerial cooperation by linking line ministries to the Sendai Framework through national focal points. Bhutan enhanced its institutional setup for information sharing across national and local levels. Cameroon issued a Decree on Territorial Units of Civil Protection, as part of the reorganization of the Ministry of Territorial Administration, and the establishment of a National Risk Observatory. Saudi Arabia put in place a Prioritized Action plan 2018-2020 to enhance reporting, and instituted mechanisms for monitoring and analyzing data. The Central African Republic is working to strengthen institutional mechanisms for emergency coordination and relief. In Colombia, a National System for Disaster Risk Management is established by law, and a focal point in each Ministry is responsible for SFM processes. Uganda has increased the engagement of subnational governments in monitoring and reporting for SFM and integrated its DRR and climate change adaptation guidelines across all sectors.
In Slovenia, DRR is informed by analysis of existing databases and national registers, and strong state level reporting. Barbados has developed a Comprehensive Disaster Management Country Work Programme (CWP) 2019-2023, aligned to both regional and global frameworks. These are some of the best practices that have emerged during the past two years, and it is noteworthy that not all these countries have sufficient resources or capacity. It is political will that drives disaster risk reduction efforts.

The outcome-focused text of the Sendai Framework demonstrates that member states have always been conscious of the need to protect their development trajectories. Member states are also increasingly aware of the importance of DRR in a world facing intensified risks driven by climate change. It will cost the world trillions of dollars over the next 10 years to achieve the SDGs. Of these trillions, much will be spent on new infrastructure. Small impact, high-frequency disasters accounted for some $69 \%$ of direct economic losses attributable to disasters during 2015-2018 (United Nations Office for Disaster Risk Reduction 2019). These are largely mitigable risks. Yet a single unmitigated disaster can erase a generation of development and wipe out billions of dollars in infrastructure and economic assets. Nothing sets back development more than disasters.

The biggest challenge we face in entering the Decade of Action is the lack of greater and more direct funding to achieve the Sendai Framework and to reduce risk. The SFM data showed that at end-September 2019, 15 recipient countries had reported receiving a mere USD 1.5 billion in bilateral and multilateral aid for DRR. Acknowledging that more comprehensive tracking of international aid for DRR is essential for generating a complete picture and identifying funding gaps, it is already clear that DRR needs a better financing strategy. Domestic sources of finance will also need to be mobilized at an equal scale to meet the targets of the Sendai Framework. In summary, it will require greater collective human and material resources, and political will than are currently in play, to achieve the targets of the Sendai Framework, reduce risk and build resilience, and to protect any progress in the achievement of the SDGs. We have only 10 more years to get there.

Open Access This article is licensed under a Creative Commons Attribution 4.0 International License, which permits use, sharing, adaptation, distribution and reproduction in any medium or format, as long as you give appropriate credit to the original author(s) and the source, provide a link to the Creative Commons licence, and indicate if changes were made. The images or other third party material in this article are included in the article's Creative Commons licence, unless indicated otherwise in a credit line to the material. If material is not included in the article's Creative Commons licence and your intended use is not permitted by statutory regulation or exceeds the permitted use, you will need to obtain permission directly from the copyright 
holder. To view a copy of this licence, visit http://creativecommons. org/licenses/by/4.0/.

\section{References}

United Nations General Assembly. 2016. Report of the open-ended intergovernmental expert working group on indicators and terminology relating to disaster risk reduction. $1 \mathrm{Dec}, \mathrm{A} / 71 /$ 644. https://www.preventionweb.net/files/50683_oiewgrepor tenglish.pdf. Accessed 5 Mar 2020.

United Nations General Assembly. 2019. Implementation of the Sendai framework for disaster risk reduction 2015-2030. Report of the Secretary General. A/74/248. https://digitallibrary.un.org/ record/3825553. Accessed 5 Mar 2020.

United Nations Office for Disaster Risk Reduction. 2005. Hyogo framework for action 2005-2015: Building the resilience of nations and communities to disasters. https://www.unisdr.org/ files/1037_hyogoframeworkforactionenglish.pdf. Accessed 5 Mar 2020.

United Nations Office for Disaster Risk Reduction. 2015. Sendai framework for disaster risk reduction 2015-2030. https://www. unisdr.org/we/inform/publications/43291. Accessed 5 Mar 2020.

United Nations Office for Disaster Risk Reduction. 2019. Global Assessment report 2019. https://gar.unisdr.org/report-2019. Accessed 5 Mar 2020. 